\title{
Pre-failure behaviour of an unstable limestone cliff from displacement and seismic data
}

\author{
J.-L. Got ${ }^{1}$, P. Mourot ${ }^{1,2}$, and J. Grangeon ${ }^{1}$ \\ ${ }^{1}$ LGIT, Université de Savoie, CNRS, UMR5559, Le Bourget-du-Lac, France \\ ${ }^{2}$ MYOTIS, 20, rue du Tour de l'Eau, 38400, Saint-Martin d'Hères, France
}

Received: 14 August 2009 - Revised: 13 January 2010 - Accepted: 22 February 2010 - Published: 15 April 2010

\begin{abstract}
We monitored the displacement and seismic activity of an unstable vertical rock slice in a natural limestone cliff of the southeast Vercors massif, southeast France, during the months preceding its collapse. Displacement measurements showed an average acceleration of the movement of its top, with clear increases in the displacement velocity and in the discrete seismic event production rate during periods where temperature falls, with more activity when rainfall or frost occurs. Crises of discrete seismic events produce high amplitudes in periodograms, but do not change the high frequency base noise level rate. We infer that these crises express the critical crack growth induced by water weakening (from water vapor condensation or rain) of the rock strength rather than to a rapid change in applied stresses. Seismic noise analysis showed a steady increase in the high frequency base noise level and the emergence of spectral modes in the signal recorded by the sensor installed on the unstable rock slice during the weeks preceding the collapse. High frequency seismic noise base level seems to represent subcritical crack growth. It is a smooth and robust parameter whose variations are related to generalized changes in the rupture process. Drop of the seismic noise amplitude was concomitant with the emergence of spectral modes - that are compatible with high-order eigenmodes of the unstable rock slice during the later stages of its instability. Seismic noise analysis, especially high frequency base noise level analysis may complement that of inverse displacement velocity in earlywarning approaches when strong displacement fluctuations occur.
\end{abstract}

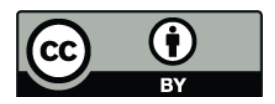

Correspondence to: J.-L. Got

(jlgot@univ-savoie.fr)

\section{Introduction}

Instability and rupture of rock masses along natural slopes are well known, but poorly understood processes which need to be investigated and characterized from various points of view. Understanding the origin and evolution of such instabilities implies the continuous monitoring of the various parameters characterizing the deformation process and its environment. Studies of rock slope stability often involve the monitoring of displacements (e.g., Kennedy and Niermeyer, 1970; Bhandari, 1988; Brunner et al., 2000; Mayer et al., 2000; Zvelebil and Moser, 2001) or morphological changes (Mikos et al., 2005; Dewez et al., 2007; Collins and Sitar, 2008) and less frequently the seismic monitoring, which was performed earlier for unstable slopes in open mines (Kennedy and Niermeyer, 1970; Hardy and Kimble, 1991 ) and more recently for natural slopes or cliffs (Willenberg et al., 2002; Senfaute et al., 2003; Kolesnikov et al., 2003; Eberhardt et al., 2004; Amitrano et al., 2005; Roth et al., 2005; Brückl and Mertl, 2006; Spillmann et al., 2007; Willenberg et al., 2008; Senfaute et al., 2009). Most of these studies were devoted to the monitoring and study of discrete seismic events. Amitrano et al. (2005) evidenced the simultaneous power-law increase and b-value decrease of the highfrequency seismicity recorded by a seismic sensor located at $\sim 5 \mathrm{~m}$ of the rupture surface during the $2 \mathrm{~h}$ preceding a $\sim 10^{3} \mathrm{~m}^{3}$ collapse in the Mesnil-Val chalk cliff, Normandie, France.

Inferring the dynamics of an unstable rock mass from passive seismic experiments, as the geodynamics was deduced from the earthquake distribution at global scale, is a recurrent question. One specificity of the study of the discrete seismic events recorded in unstable rock slopes is that the low magnitude of the events, their dominant frequency and the medium attenuation make the recording of discrete events by multiple sensors difficult (see e.g., Senfaute et al., 2003; Amitrano et al., 2005; Spillmann et al., 2007). Seismic networks should

Published by Copernicus Publications on behalf of the European Geosciences Union. 

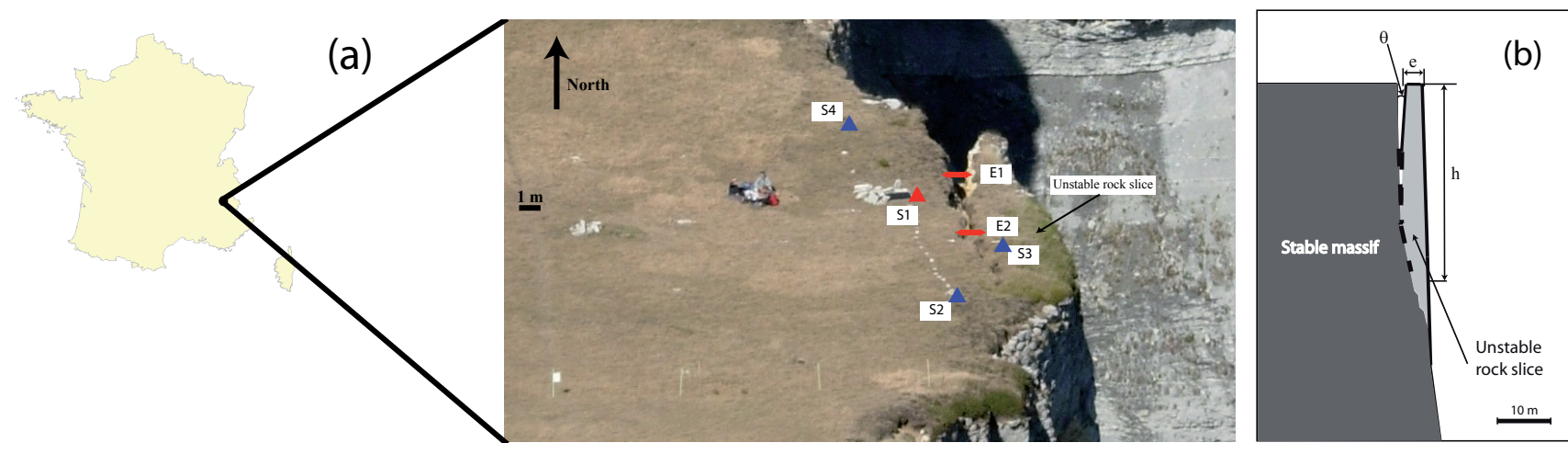

Fig. 1. (a) Geographic location and photographic northward view of the experimental site, showing the stable massif and the unstable rock slice. S1: three-component, S2, S3, S4: vertical geophones; E1, E2: extensometers. S1, E1, E2 operated from 1 August, and S2, S3, S4 operated from 11 October; both stopped 10 November, some days before the collapse of the unstable rock slice. (b) Vertical cross-section of the investigated rock slope, showing the stable massif and the unstable rock slice. Thick dashed lines represent areas where rock bridges are likely to exist.

be simultaneously very dense and extended at the surface and at depth, to allow the location of such very small earthquakes and the characterization of the state of stress and deformation in a significant volume. Field maintenance of such networks is often a difficult task, which makes them unrealistic for long durations and poorly accessible unstable rock masses. Although studying well-recorded discrete seismic events has proven to be a powerful tool for characterizing large crustal or lithospheric volumes, other approaches might be attempted to take profit of the information brought by the seismic energy radiation when recorded by a small number of sensors. Seismic noise analysis may be one of these approaches. Seismic noise correlation has been used at large scale (e.g., Shapiro et al., 2005) to infer lithospheric structures. Other methods, including the determination of spectral or horizontal-to-vertical (H/V) ratio modes, have been used at smaller scales for resonance studies of buildings, site effect estimation and engineering seismology (see e.g., Méric et al., 2007). Such analyses might be used to infer temporal variations in elastic properties of unstable rock masses as it has been already used to infer temporal variations on volcanoes (Brenguier et al., 2008) - or eventually in spectral modes, from a limited number of seismic sensors.

In this study we will investigate the rupture process of a vertical and sharp rock slice in a natural limestone cliff by using both environmental and displacement data, and seismic noise measurements to infer rock fracture parameters and identify new seismic parameters necessary to characterize the time evolution of the fracture process.

\section{Data}

Data were collected at and near the summit of the natural cliff of Chamousset, Chichilianne, South-East Vercors, in the French Alps (Fig. 1). The cliff is about $250 \mathrm{~m}$ high. It is con- stituted by lower Barremian bioclastic, porous, limestones, whose top is formed by the superposition of subhorizontal decimetric beds, subject to weathering and fragmentation at the surface. The top of the cliff is subhorizontal and constitutes the eastern border of the Vercors plateau; it reaches the altitude of $1850 \mathrm{~m}$. The cliff delaminates recurrently along $\sim$ NS vertical planes as rock slices whose thickness is a few meters only, whereas the two other dimensions may reach 50 to $100 \mathrm{~m}$ long. During mid-July 2007 an approximately 5$\mathrm{m}$ wide, 40-m long and 50-m high unstable rock slice was identified along this cliff. A small autonomous extensometric and mobile seismological network was rapidly installed (1 August) on and around the top of this unstable volume (Fig. 1). Two GEFRAN cable extensometers were installed horizontally, normal to the walls at the top of the vertical fissure which separated the unstable rock slice from the stable massif. The northern extensometer was installed in the largest part of the crack and had a measurement extent of $375 \mathrm{~mm}$, whereas the southern extensometer measurement extent was $100 \mathrm{~mm}$. Thermal variation of the mechanical and electrical transduction induces a bias of \pm 0.2 (resp. 0.1) $\mathrm{mm}$ for the $\mathrm{N}$ (resp. S) extensometer, for a $\pm 10^{\circ} \mathrm{C}$ temperature variation. One vertical $4.5-\mathrm{Hz}$ GS-11D (coil resistance $4000 \Omega, 18200 \Omega$ shunt damping, intrinsic sensitivity $80 \mathrm{~V} / \mathrm{m} / \mathrm{s}$ ) Geospace seismometer was installed at the top of the unstable rock slice (S3, Fig. 1), whereas two other vertical and one 4.5-Hz Geospace three-component seismometers were installed on the stable part of the rock mass. One of them was close to the southern end of the rock slice (S2, Fig. 1). Transfer functions of the seismometers are flat from 10 to $1000 \mathrm{~Hz}$. 16-bit data were continuously recorded at a 1$\mathrm{kHz}$ sampling rate on a $120-\mathrm{Gb}$ hard disk. Spacing between seismic sensors was chosen to be about $10 \mathrm{~m}$. Extensometric data were sampled at $1 \mathrm{kHz}$, then averaged over 5-min intervals, so that high-frequency random noise is negligible 
in these measurements. The network operated with interruptions and changes (Table 1) from 1 to 21 August and from 11 October to 10 November, less than one week before the collapse of the unstable rock slice. The date of the collapse is necessarily comprised between 10 November (when the acquisition system stopped) and 17 November (date of the visit during which it was visually established that the rock slice was collapsed).

\section{Results of extensometric measurements and continuous seismic recording}

At the beginning of the experiment, the unstable rock slice was already partly detached from the stable massif (Fig. 1), as the crack width reached about $1 \mathrm{~m}$ at its northern end. No vertical offset was observed between the stable and unstable compartments at that time, nor later. Extensometric data show a general increase of the rock slice - massif distance from August to October (Fig. 2). Displacement rate increased from an average of $0.7 \mathrm{~mm} /$ day in August to an average of $3 \mathrm{~mm} /$ day in October-November. Second-order displacement variation may be first characterized by an average acceleration of $0.0155 \mathrm{~mm} / \mathrm{day}^{2}$ during the whole time period. These data were approximately fitted by a time power law $t^{\alpha}$ where $\alpha \sim 2$. A striking second-order feature of the displacement variations is the increase, by a factor of 3 to 5 , in displacement rate occurring during rain, frost or merely cold time periods, which correlates with an increase in seismicity rate. A thorough inspection of the respective timing of displacement, seismicity, temperature and rainfall data shows that deformation systematically occurs when temperature falls, and not only when rain or frost occurs, even if these later conditions are related with increased deformation. Interestingly the inverse velocity mimics the average temperature variations (Fig. 2), and seismicity begins to increase when average temperature begins to decrease, before rain or frost occurs. Discrete seismicity (Fig. 2c) was detected in the continuous records using a STA (short term average)/LTA (long term average) algorithm (Allen, 1982), the strongest seismic crises being controlled manually. Given the geometry of the moving rock slice, a relatively weak proportion of the seismic energy excitated the S3 vertical sensor, leading to recording less seismic events. Detailed results of the study of the discrete seismicity will be presented and discussed in a specific article.

One of the aim of this experiment was to investigate the content of the seismic noise recorded by short-period seismometers, especially at relatively high frequency, to determinate if seismic noise may provide a mean to monitor unstable rock slopes. In that aim, continuous seismic records were analyzed both in the time and frequency domains. Recorded noise may be partitioned in a random part caused by various external causes, and a seismic part bearing evenutally some deterministic information on the rupture process or on
Table 1. Synthesis of the installation and maintenance operations.

\begin{tabular}{ll}
\hline Date & Operation \\
\hline 1 Aug 2007 & $\begin{array}{l}\text { Installation S1 (3C seismic sensor). } \\
\text { Installation E1, E2 (extensometers). }\end{array}$ \\
11 Oct 2007 & $\begin{array}{l}\text { Installation S2, S3, S4 (vertical seismic sensors). } \\
\text { Change regulator - replace disk. }\end{array}$ \\
5 Nov 2007 & $\begin{array}{l}\text { Add solar pannel - remove snow. } \\
\text { Replace disk. }\end{array}$ \\
\hline
\end{tabular}

the propagation medium. In order to reduce, as far as possible, the variance brought by the external random noise and to evidence the eventual information beared by the seismic noise, it is necessary to perform averaging over long time series, assuming that the seismic noise has stationary properties over a sufficient duration. To represent most of the information contained in the signal in a compact form, we chose to compute the averaged smoothed periodogram of each hour of record (the "periodogram" is the module of the Fourier Transform; see, e.g., Jenkins and Watts, 1968). We first computed the smoothed periodogram of $2^{14}$-sample time windows $(16.384 \mathrm{~s}$ of signal sampled at $1 \mathrm{kHz}$, tapered with a high-dynamic Nuttal window; the time-tapering of the seismic data induces a frequency smoothing). Frequency sampling rate of the resulting spectrum is therefore $0.06 \mathrm{~Hz}$, the effective resolution of the Nuttal-smoothed periodogram being $0.5 \mathrm{~Hz}$. Periodograms were then averaged ("stacked") over one-hour records using 330 50\%-overlapping $16.384 \mathrm{~s}$ long time windows. By this process the spectral random noise level is reduced by a factor of 10 to 15 , and deterministic components - which may be lower than the random noise recorded in a short time window - may be more easily identified. Periodograms were corrected (in the frequency domain) from the sensor transfer function. Below $4 \mathrm{~Hz}$ the averaging process evidences mainly the low-frequency noise of the recording chain (therefore the periodogram is interpretable only above $\sim 4 \mathrm{~Hz}$ ). Averaged smoothed periodograms were computed during $560 \mathrm{~h}$ from 11 October to 10 November 2007 , for every seismic channel.

Results computed for the S2 sensor (Fig. 3) show that most of the recorded seismic energy was concentrated in the first $120-\mathrm{Hz}$ spectral band, and occur during intermittent crises, where dominant frequencies are close to $25 \mathrm{~Hz}$ and $40-50 \mathrm{~Hz}$. Maximum spectral amplitudes recorded on the top of the unstable rock slice were 2 to 5 times lower than those recorded on the stable massif. Average amplitudes are high when seismic events are numerous, displacement rate is high and temperatures are low (Figs. 2-3). Correlation between the seismic energy recorded on the stable and unstable parts of the massif is poor. We computed the base noise level (Vila et al., 2006) by finding the minimum value, 
(a)
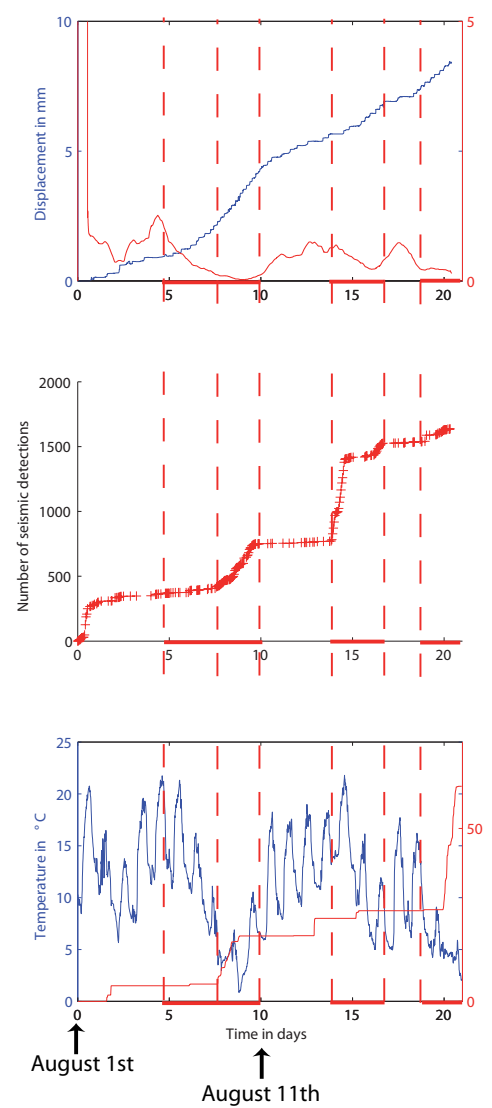

(b)
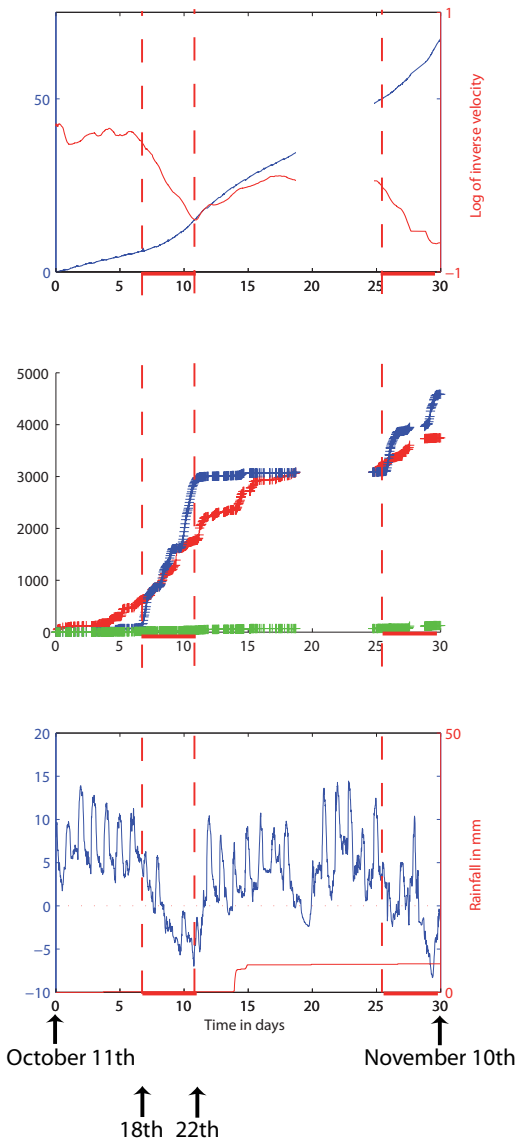

(c)

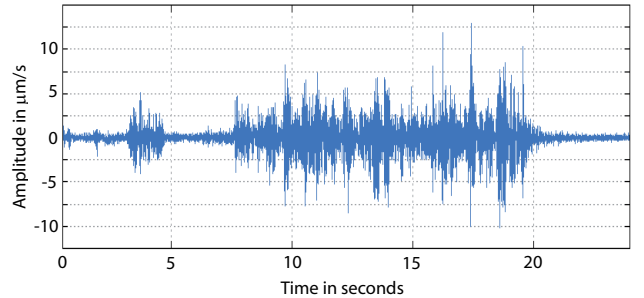

Fig. 2. Top: plot of displacement data (blue line: displacement measured by E1 extensometer, red line: log of inverse velocity); center: cumulated number of seismic detections (red crosses: vertical component of S1 geophone; blue crosses, S2 vertical geophone; green crosses: S3 vertical geophone); bottom: temperature (blue line) and rainfall (red line). (a) From 1 to 21 August; (b) from 11 October to 10 November. Red vertical dashed and horizontal thick lines represent the time periods during which average temperature drops, seismicity and displacement increase. (c) Plot of a typical seismic event occurring during a seismic crisis.

for each frequency sample of the periodogram, over a time series of $33050 \%$-overlapping $16.384 \mathrm{~s}$ s-long windows (onehour record). Remarkably, the base noise level slowly but steadily increases with time (Fig. 3), especially at high frequency. This increase is stronger at low frequency and for the S3 sensor, installed at the top of the unstable rock slice: measurements reveals an amplitude relative variation of $26 \%$ and $14 \%$ respectively at low and high frequency on the stable massif ( $\mathrm{S} 2$ sensor), whereas it is 33\% and 17\% (resp. at low and high frequency) on the unstable rock slice (S3 sensor). Rate of the periodograms and base noise level at high frequency is remarkably stable between seismic crises. The amplitude of periodograms and base noise level tend to decrease at the end of the recording period, even at high frequency. We represented the amplitude of the noise (seismic signal recorded between high-amplitude crises) as a function of frequency (Fig. 4) for various time intervals, chosen outside periods of high-amplitude seismic signal from 11 October to 10 November. Spectral modes at 5, 8, 10, and $12 \mathrm{~Hz}$ are present since 11 October; they amplify with time. New modes appear above $15 \mathrm{~Hz}$, up to $50 \mathrm{~Hz}$, just before the final rock slice collapse. They are more sharply individualized on the unstable rock slice than on the stable massif, although the amplitude of the noise is higher on the massif than on the rock slice at frequencies higher than $10 \mathrm{~Hz}$. Noise level clearly increases with time between 11 October and 10 November, below $10 \mathrm{~Hz}$ by a factor of 30 to 50 , above $10 \mathrm{~Hz}$ by a factor of $\sim 20$ on the stable massif, and a factor of $\sim 3$ on the unstable rock slice. Modes are strikingly strongly amplified and sharper above $10 \mathrm{~Hz}$ on the unstable rock slice than on the stable massif, just before the final rupture. 


\section{Discussion}

Due to the specific geometry and deformation mode of the unstable rock mass, deformation data may be used to infer macroscopic mechanical characteristics of the rupture that are rarely computed, that will be useful for further modelling. Both observations (displacement, seismicity, seismic noise levels) need to be compared with environmental measurements (temperature and rain) to understand the origin and evolution of the deformation process, and eventually identify parameters which may be useful for early-warning approaches.

\subsection{Analysis of extensometric data}

\subsubsection{Low-level acceleration and rock slice equilibrium}

From the low acceleration during at least three months we deduce that the unstable rock slice was very close to the limit equilibrium during several months before its final failure. As most of the displacement of the rock slice was horizontal, we can hypothesize that the movement was a rotation (a hinged toppling movement) around a horizontal axis, which coincidates with the lower end of the vertical crack observed, rather than sliding along the crack wall. The volume of the moving rock slice being $\sim 10^{4} \mathrm{~m}^{3}$, its density $2.510^{3} \mathrm{~kg} / \mathrm{m}^{3}$, its heigth $h$ equal to $25-50 \mathrm{~m}$ leads to compute a moment of inertia $J \sim 10^{10} \mathrm{~N} / \mathrm{m} / \mathrm{s}^{2}$. Taking the linear acceleration equal to $2 \times 10^{-15} \mathrm{~m} / \mathrm{s}^{2}$ at the top of the rock slice, we find that the algebraic sum of the driving moment $M_{\mathrm{d}}$ and the resistant moment $M_{r}$ is $\Sigma M=M_{\mathrm{d}}-M_{\mathrm{r}}=J \ddot{\theta} \sim 10^{-6} \mathrm{~N} / \mathrm{m}$, where $\ddot{\theta}$ is the angular acceleration. Driving and resistant moments are therefore extremely close, which explains why rain and temperature may contribute to displacement rate. In the hypothesis where the weight of the rock slice is the driving force of the movement, taking a summit horizontal displacement of $\sim 1 \mathrm{~m}$, would lead to find $M_{\mathrm{d}} \sim 10^{8} \mathrm{~N} / \mathrm{m}$, that is, $\frac{\Sigma M}{M_{\mathrm{d}}} \sim 10^{-14}-$ and therefore a safety factor extremely close to 1 .

Voight (1989) proposed to use the inverse of the displacement rate as a measure of the dynamics of the unstable system, providing a tool for an eventual prediction of the time to failure. Figure $2 \mathrm{a}-\mathrm{b}$ (top) shows that the inverse of the displacement rate decreases, in average, as $t^{-1}-$ its logarithm exhibits a first order linear trend. However, second order variations due to unstability and weather conditions are so strong that this approach can not be used easily, in this case, to infer a reliable estimate of the actual time to failure.

\subsubsection{Estimation of rock fracture parameters}

Measurements made during the progressive rupture process of the rock mass allow us to infer the order of magnitude of some quantities that are rarely estimated at that scale, which (a)

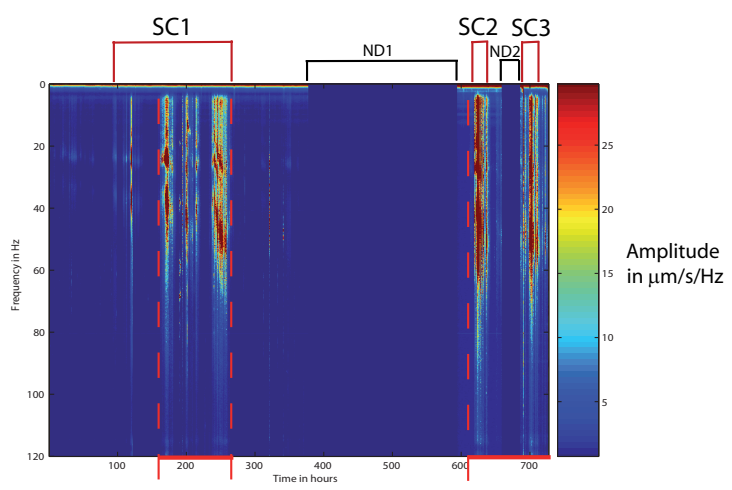

(b)

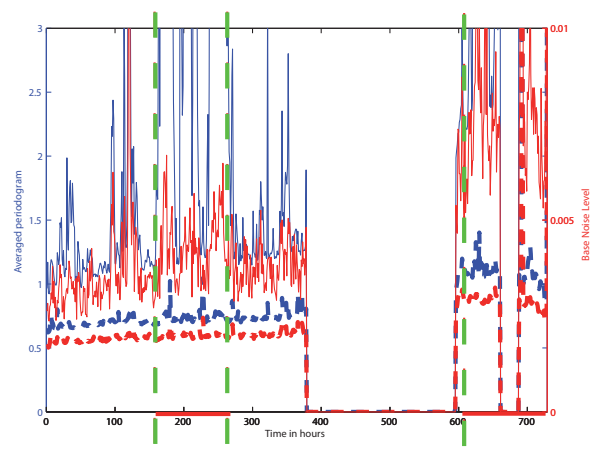

(c)

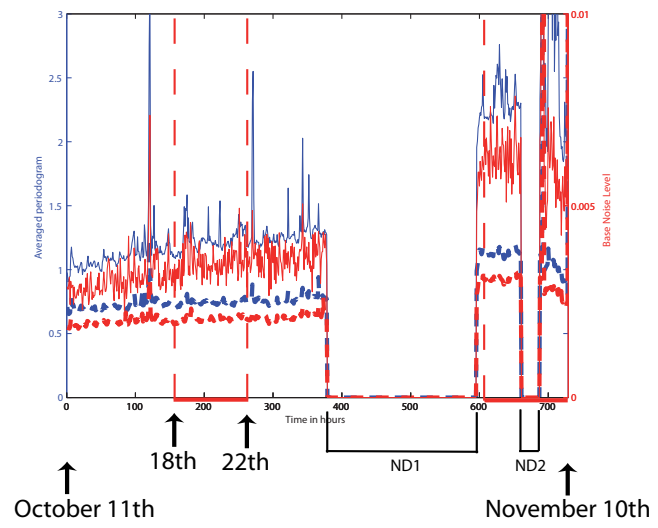

Fig. 3. (a) Spectrogram built from the juxtaposition of the periodograms computed (see text for details) from 11 October to 10 November for the $\mathrm{S} 2$ seismometer records, stable massif. (b) and (c): averaged smoothed periodograms (blue lines) and base noise level (red lines) as a function of time from 11 October to 10 November, for two frequency bands: $4-10 \mathrm{~Hz}$ (solid line) and $120-500 \mathrm{~Hz}$ (dashed line): (b) stable massif, S2 seismometer, (c) unstable rock slice, S3 seismometer. ND: no data; SC: seismic crisis. Red vertical dashed and horizontal thick lines represent the time periods during which average temperature drops, seismicity and displacement increase. Seismic crises induce high amplitudes in the periodograms.

is intermediate between earthquakes and laboratory experiments. Most of the surface displacement occurring during several months being horizontal and normal to the fracture walls, the rupture mechanism may be hypothesized to be 
(a)

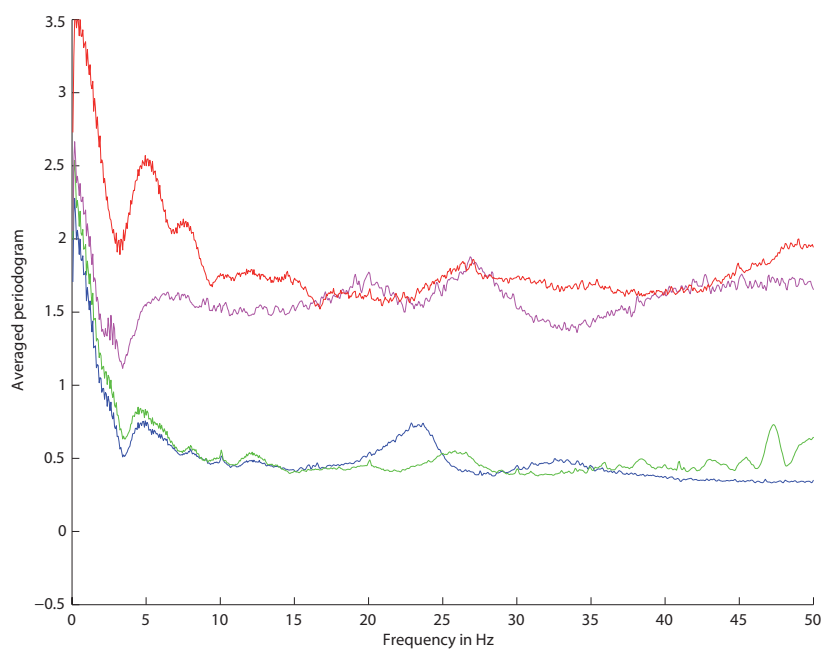

(b)

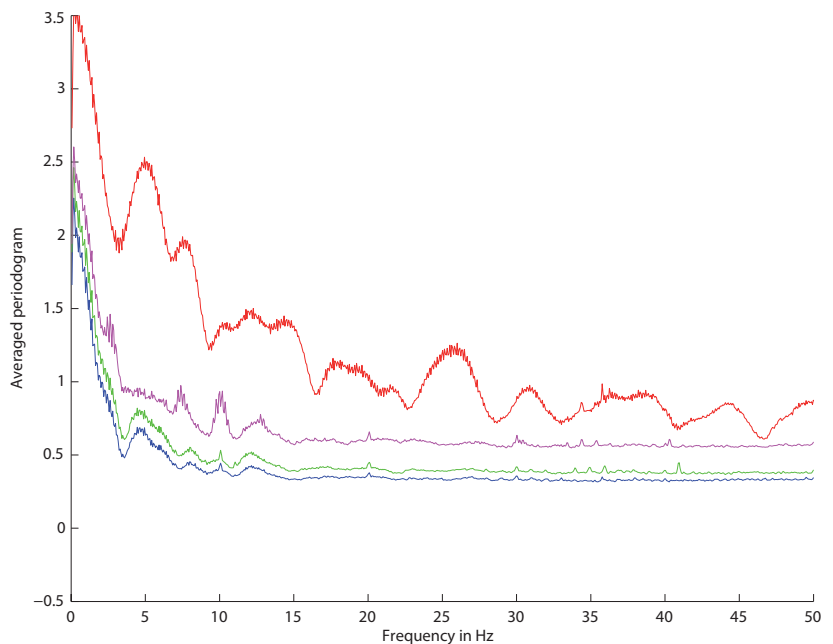

Fig. 4. Averaged seismic noise amplitude as a function of frequency, for various time periods, from 11 October: $(1-50 \mathrm{~h}$ : blue; 320-360 h: green; 600-630 h: magenta; 700-728 h : red) ; (a) stable massif, S2 seismometer; (b) unstable rock slice, S3 seismometer.

Mode I. In that case the fracture energy release rate $G$ is written :

$G=\frac{d W_{\mathrm{s}}}{d S}$

where $d W_{\mathrm{s}}$ is the work used while creating the new fracture surface $d S$.

$G$ may be expressed as a function of parameters observed on the field, which allows us to estimate an order of magnitude for $G$ in that context. Hypothesizing that the rock slice (mass $m$ and angular abscissa $\alpha$ ) moves subhorizontally under the effect of its own weight, the work done after the initiation of the rupture is

$W_{\mathrm{m}}=\int_{0}^{\theta} m g \sin \alpha \frac{h}{2} d \alpha$

where $\theta$, expected to be small, is the angular abscissa at the rupture of the rock slice (that is, at the end of its quasi-static displacement), and $g$ is the gravity acceleration intensity.

For small values of $\alpha, W_{\mathrm{m}}$ becomes

$W_{\mathrm{m}} \sim \frac{1}{4} m g h \theta^{2}$

In the case the work yield by the weight is used to create the new fracture surface,

$G \sim \frac{1}{4} \rho g e h \theta^{2}$

for small $\theta, e$ being the thickness of the rock slice, or $G \sim \frac{1}{4} \rho g \frac{e}{h} u^{2}$, where $h$ is the height, and $u$ the average summit horizontal displacement of the rock slice. Taking $\rho \sim 2500 \mathrm{~kg} / \mathrm{m}^{3}, g \sim 10 \mathrm{~ms}^{-2}, e \sim 5 \mathrm{~m}, G$ varies between 300 and $3000 \mathrm{~J} / \mathrm{m}^{2}$ for $h$ varying between 25 and $50 \mathrm{~m}$, and averaged values of $u$ with distance along the surface crack varying between $\sim 0.75$ and $\sim 1.5 \mathrm{~m}$. This order of magnitude falls between those found from laboratory experiments and those found from earthquake source studies (e.g., Scholz, 2002; Ohnaka, 2003; Chambon et al., 2006), and scales well with the size of the rupture process.

The limit tensional stress $\sigma_{\mathrm{t}}$ which may be resisted by a rock mass of macroscopic Young modulus $E$, containing a fracture of height $h$ is (e.g., Lawn, 1993)

$\sigma_{\mathrm{t}}=\left(\frac{E G}{\pi h}\right)^{\frac{1}{2}}$

Using Eq. (4) and considering that $E=\frac{5}{6} \rho V_{\mathrm{p}}^{2}$ for a Poisson ratio of 0.25 ( $V_{\mathrm{p}}$ : seismic P-wave velocity), a macroscopic $\sigma_{\mathrm{t}}$ may be expressed directly from the measured quantities:

$\sigma_{\mathrm{t}}=\frac{1}{2}\left(\frac{g e}{\pi}\right)^{\frac{1}{2}} \rho V_{\mathrm{p}} \theta$

We find an order of magnitude for the macroscopic tensional rock strength $\sigma_{\mathrm{t}} \sim 100 \mathrm{kPa}$ for $V_{\mathrm{p}} \sim 1000 \mathrm{~m} / \mathrm{s}, \rho \sim 2500 \mathrm{~kg} / \mathrm{m}^{3}$, $g \sim 10 \mathrm{~ms}^{-2}, e \sim 5 \mathrm{~m}$, and an average $\theta \sim 0.02 ; \sigma_{t}$ remains lower than $500 \mathrm{kPa}$ for higher values of the average $\mathrm{P}$-wave velocity.

To validate these orders of magnitude, we computed the order of magnitude of the characteristic weakening displacement $u_{\mathrm{c}}$ for which the rock mass strength is relaxed on the whole rupture surface. It may be defined as the average displacement needed to create the fracture surface and consume the fracture energy when relaxing completely the rock mass strength. When the rock mass ruptures totally, the rock mass strength drops from the macroscopic $\sigma_{t}$ to nearly zero. 
$G$ may be expressed, from this strength drop $\sigma_{t}$, as the energy required to fracture the total rupture surface (Palmer and Rice, 1973; Rice, 1980)

$G=\int_{0}^{u_{\mathrm{c}}} \sigma_{\mathrm{t}} d u$

Therefore, considering a constant $\sigma_{\mathrm{t}}$ during the movement,

$u_{\mathrm{c}} \sim \frac{G}{\sigma_{\mathrm{t}}}$

which gives $1-10 \mathrm{~mm}$ as a typical range of magnitude for $u_{\mathrm{c}}$. Values of $G$ comprised between 300 and $3000 \mathrm{~J} / \mathrm{m}^{2}$ and $u_{\mathrm{c}} \sim 1-10 \mathrm{~mm}$ fit quite well in the fracture energy release rate - characteristic weakening displacement relationship found by numerous authors (see e.g. Fig. 5 of Chambon et al., 2006). Systematic estimation of $G$ and $\sigma_{\mathrm{t}}$ could be performed in similar contexts to infer reliable values for these parameters, which are needed to evaluate how such rock masses may be close to failure.

\subsubsection{Action of fluids and frost}

The computed orders of magnitude show that the rock strength near the fracture tip is low $(\sim 100 \mathrm{kPa})$, as is the horizontal confining stress, caused by the weight of the slice at that depth $(\sim 300 \mathrm{kPa})$. Extensometric data show that the rock slice is extremely close to the limit equilibrium, and that significant changes in displacement rates and seismicity rates are realized during limited time periods, corresponding to drops in average temperature (Fig. 2). It is remarkable that increased deformations seems to be correlated more with temperature drops than with passing through a given temperature threshold. Warm air contains quantities of water vapor, and lowering the temperature induces water condensation. Wetness and water saturation can decrease the value of the rock strength of porous limestones near the fracture tip by 20 to $70 \%$ (e.g., Rutter, 1972; Parate, 1973; Vutukuri, 1974; Atkinson, 1979; Atkinson and Meredith, 1987; Homand and Shao, 2000; Rhett and Lord, 2001; Gueguen and Boutéca, 2004; Risnes et al., 2005; Ghabezloo and Pouya, 2006) especially at low temperatures $\left(0-10^{\circ} \mathrm{C}\right)$. Strength of porous limestones may decrease by almost $50 \%$ when their degree of saturation reaches only $10 \%$, and their tensile strength may be as low as $500 \mathrm{kPa}$ at the sample scale (Ghabezloo and Pouya, 2006). This process is often described as water weakening, that is, stress corrosion due to physico-chemical reactions - reduction of the calcite surface energy by the polar electrical interaction between water and calcite grains, a process which leads to subcritical crack growth. Together with the tensile state of stress, it may also contribute to increase the local micro-rupture process in the rock (e.g., Lawn, 1993), and may explain the concomitance of the beginning of the increase in seismicity rate with the lowering of temperature: reduction of rock strength moves the rock slice away from equilibrium. In the case where some fractures would be saturated by water or ice at the confining pressure, the pressure inside the fractures may eventually contribute to exceed rock strength and confining pressure and create new fracture surface, if permeability is sufficiently low.

\subsection{Analysis of the continuous seismic records}

\subsubsection{Emergence of eigenmodes in noise spectrum}

Two main features may be extracted from the analysis of the continuous seismic records: (1) the presence of modes in the noise spectrum, whose amplitude is increasing on the unstable rock slice before the final rupture, and (2) the progressive increase with time in seismic noise amplitude. Seismic modes from noise records on the unstable rock slice probably reveal eigenmodes of the rock slice. Eigenfrequencies of the flexion mode $i j$ of a plate may be expressed as (from Blevins, 2001)

$f_{i j}=\frac{\pi e}{2}\left(\left(\frac{i}{a}\right)^{2}+\left(\frac{j}{b}\right)^{2}\right) \sqrt{\frac{E}{12 \rho\left(1-v^{2}\right)}}$

where $i$ and $j$ are the numbers of vibration antinodes (or half-wavelengths) following respectively the dimensions $a$ and $b, e$ the thickness, $E$ the Young modulus, $v$ the Poisson ratio and $\rho$ the density of the plate. Let $\lambda_{a}=\frac{a}{i}$ and $\lambda_{b}=\frac{b}{j}$ be the characteristic length of the antinodes following the dimensions $a$ and $b, f_{i j} \sim \frac{1}{\lambda_{a}^{2}}+\frac{1}{\lambda_{b}^{2}}$ for a given material and plate thickness. Therefore $f_{i j}$ increases for shorter antinodes. An order of magnitude for the fundamental eigenfrequency $(i=j=1$ ) for $a=b \sim 50 \mathrm{~m}, E \sim 10 \mathrm{GPa}, v \sim 0.25$, $\rho \sim 2500 \mathrm{~kg} / \mathrm{m}^{3}, e \sim 5 \mathrm{~m}$ is $4 \mathrm{~Hz}$. Frequencies of $\sim 10,20,25$, 30,37 , and $50 \mathrm{~Hz}$ may correspond respectively to $f_{12}, f_{13}$, $f_{23}, f_{14}, f_{24}$, and $f_{34}$. A frequency of $50 \mathrm{~Hz}$ corresponds to an antinode length of $\sim 15 \mathrm{~m}$.

The fact that the amplitude and number of higher frequency eigenmodes increases with time close to the failure therefore might indicate an increase in the amplitude and number of antinodes induced by the progressive separation of the rock slice from the stable massif. In that case rock breaks, creating discontinuities and rock bridges that are vibration nodes. No second order eigenfrequency variation larger than the uncertainty, analog to frequency sliding, was detected. Most of the spectral variations arise from changes in eigenmode amplitudes. The amplitude of the eigenmodes of a damped linear elastic system with one degree of freedom may be written (e.g. Snowdon, 1968; Jones, 2001):

$$
X \sim \frac{S_{0}}{\alpha \sqrt{\frac{E}{m}}}
$$

where $S_{0}$ is the amplitude of the excitation, $\alpha$ is the damping coefficient, $E$ is the Young's modulus and $m$ is the mass 
of the elastic system. As no increase in the amplitude is revealed around the higher eigenmode frequencies on the stable massif (Fig. 4a), we may assume that the input seismic noise is relatively stationary with frequency at that time. The increase in amplitude on the unstable rock slice may therefore be related to the decrease in Young's modulus and more probably in damping. Damping is indeed due to the contact between the rock slice and the stable massif, involving friction and energy loss which progressively decreases when the rock slice moves away from the stable massif. Therefore the increase in modal amplitude at high frequency is coherent with the progressive and heterogeneous decoupling of the unstable rock slice from the stable massif interface.

\subsubsection{Steady increase of the base level of the noise spectrum at high frequency}

Variations in continuous recordings of seismic amplitudes (e.g., RSAM measurements) have been widely used to monitor the eruptive activity of volcanoes (e.g., Endo and Murray, 1991; Cornelius and Voight, 1994). These measurements however concern both signal and noise amplitudes. Temporal variations in noise records related to eruptions were also recently observed (Brenguier et al., 2008); more specifically, variations in the "base level" of the spectrum of seismic noise recorded by broad band stations were already observed by Vila et al. (2006) before volcanic eruptions. Figure 3 shows that the averaged smoothed periodogram and base level of the noise at high frequency are steadily increasing during the one-month period preceding the rock slice rupture, an observation which is close to the one made by Vila et al. (2006) before volcanic eruptions. Origin of these temporal variations is an open question, although it is likely to be related to the sensu lato deformation process under some stress changes.

Continuous seismic recording during $378 \mathrm{~h}$ from 11 to 27 October shows a striking linear increase of the base noise level, outside the periods of seismic crisis (Fig. 3). It is quite remarkable that the same increase rate is found before and after the periods of seismic crisis. This increase is stronger at lower frequencies, but is clearly found even in the highest frequency band $(120-500 \mathrm{~Hz})$. The fact that the increase in base seismic noise level occurs as a stationary process in large frequency bands without generating recordable impulsive discrete events, leads to hypothesize that it originates directly or indirectly in the slow growth of fractures.

Two non-exclusive causes may a priori contribute to the variations of the base noise level: one may be related to the seismic noise production, and the other to the propagation medium.

Changes in the medium could induce changes in the rock mass transfer function through the progressive individualization and amplification of modes. This may occur especially at low frequency and could explain that the noise base level increase more at low $(4-10 \mathrm{~Hz})$ than at high $(120-500 \mathrm{~Hz})$ frequency (Fig. 3). In that case, this variation could be an early evidence of the mode shape finally found (Fig. 4b). It is less likely to occur at high $(120-500 \mathrm{~Hz})$ frequency where no mode is evidenced.

Concerning the seismic noise production, the remarkable invariance of the increase rate of the base noise level between periods of seismic crises shows that two processes are at work for producing seismic energy. The first process causes the steady-state energy release; as it does not generate recordable discrete seismic events, it may be performed at subcritical energy release rate, revealing the long-term, lowpower, quasi-static growth of fractures close to the equilibrium between the elastic tensional stresses accumulated at the tip of the cracks and the rock strength. The second process causes the high seismic power release constituted by the occurrence of discrete events when the critical energy release rate $G_{\mathrm{c}}$ is reached; it reveals that the system becomes out-ofequilibrium. Rain or low temperature periods (leading to increased wetness, condensation or frost) may induce the loss of rock strength, the rupture of equilibrium and the local acceleration of the process which may explain some correlation between deformation and rainfall/temperature. The fact that the base noise level remains steadily increasing between periods of strong discrete event occurrence, displacement, rain and/or frost is a further evidence that this increased deformation occurred through the decrease of the rock strength rather than through the increase of the applied stresses. When rock is close to failure the deformation pattern of the rock slice is at least partly controlled by the rock strength weakening. The base noise level seems to be more linearly related to the stresses applied on a given volume, larger than the tip of the crack.

Though limited, acceleration periods may account for a significant part of the deformation. Emergence of such acceleration periods might evidence that the rock slice entered in a characteristic phase of instability. However recorded discrete seismic events appear to be only a degenerescence-limited in space and time- of an otherwise quasi-static process. They do not imply necessarily a generalized change in the rupture process, able to provoke a change in base noise level. Therefore in early-warning systems both parameters (total seismic energy release and base noise level, and not only the first one) should be inspected, taking into account they evidence two different aspects of the rupture. This understanding may help to mitigate the number of false alarms in early warning issues. Notice also that both noise amplitudes are decreasing in the last $50 \mathrm{~h}$, during a cold period. A conjecture is that most of the rupture work has been accomplished before that time and that a stage is reached where the emission of seismic energy is limited by the (diminishing) volume on which the stresses apply. In the first stage the actual emissive volume is large, and the seismic attenuation limits the apparent emissive volume (which appears to be constant); in the last stage the actual emissive volume becomes smaller, therefore actual 
and apparent emissive volume are equal (and limited by the geometry of the source). A reduction of the base noise level also implies that the seismically active stresses do not vary too strongly with the volume on which they apply: they remain concentrated around the tip of the cracks, and the crack density does not increase strongly. Another explanation may be that stress accumulation may migrate to another, more distant place, for which the transfer function of the rock mass attenuates more strongly the seismic signal. These questions will be examined more thoroughly in further works.

\section{Conclusions}

The continuous recording of displacement and seismic activity during a period of time preceding the collapse of a thin rock slice in a natural cliff of porous bioclastic limestone in the southeast Vercors massif, southeast France, and its careful investigation, allowed to evidence a set of correlated observations. Displacement measurements showed an average acceleration during three months; displacement velocity and discrete seismic event production rate strongly increased during time periods of lowering temperatures - but not necessarily during rain or frost time periods. We computed averaged smoothed periodograms and base noise level (Vila et al., 2006) of the seismic records for the one-month period preceding the final collapse. Periods of seismic crises, which give high amplitudes in periodograms, do not change strongly the base noise level at high frequency, whereas a steady increase of this level is measured throughout most of the recording period. Our interpretation is that these periods of deformation crises are related to the weakening of the rock, due to weathering ("water weakening") induced by the water vapor condensation, rain or frost, rather than to a rapid increase in applied stresses. Thousands of similar cycles applied to a rock mass subject to decompression may have provoked fatigue and damage up to its final collapse. This weakening is however not generalized in a large volume: after each of the accelerated deformation periods, deformation rate returned to its background level, and the unstable rock slice didn't collapse. Such strong and frequent second-order variations make very uncertain the use of inverse displacement velocities to issue an early warning. During the same period no variations were recorded in the high-frequency base noise level rate, which may make this smooth and robust parameter a candidate for discriminating false alarms in early-warning approaches. During the last two days of the recording period (about within one week before the final collapse), the base noise level dropped, which may be conjectured as the result of the reduction of the seismic emission volume. Simultaneously, eigenmodes appear in the seismic records of the sensor installed at the top of the unstable rock slice, which is coherent with the reduction of the rock bridges between the unstable rock slice and the stable rock massif. This later observable may also be proposed as a parameter in early-warning approaches. As a conclusion, detecting and monitoring very active unstable rock masses may bring rich information for understanding the physical processes at work. Further experiments will be needed to reiterate similar measurements and observations, and confirm/infirm our results.

Acknowledgements. We thank the Parc Naturel Régional du Vercors staff to have warned our laboratory for this impending rock slide event, and Didier Hantz to have communicated widely the information. We thank Thierry Villemin and Stéphane Jaillet for providing us LIDAR survey results and their geometrical interpretation.

Edited by: A. Günther

Reviewed by: L. Blikra, S. Mertl, and another anonymous referee

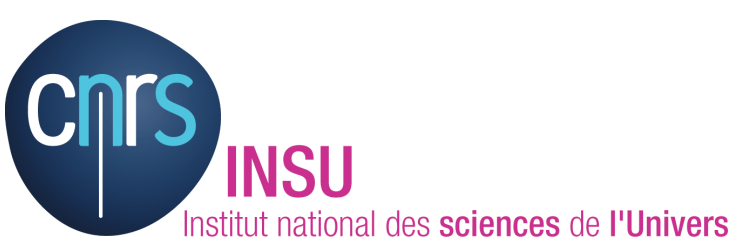

The publication of this article is financed by CNRS-INSU.

\section{References}

Allen, R.: Automatic phase pickers: their present use and future prospects, B. Seismol. Soc. Am., 72(6), 5225-5242, 1982.

Amitrano, D., Grasso, J.-R., and Senfaute, G.: Seismic precursory patterns before a cliff collapse and critical point phenomena, Geophys. Res. Lett., 32, L08314, doi:10.1029/2004GL022270, 2005.

Atkinson, B. K.: A fracture mechanics study of subcritical tensile cracking of quartz in wet environments, Pure Appl. Geophys., 117, 1011-1024, 1979.

Atkinson, B. K. and Meredith, P. G.: The theory of subcritical crack growth with applications to mineral and rocks, in: Fracture Mechanics of Rock, edited by: Atkinson, B. K., Academic Press, London and San Diego, 111-166, 1987.

Bandhari, R. K.: Some lessons in the investigation and field monitoring of landslides, in: 5th International Sympsium on Landslides, Lausanne, Bonnard, C., Balkema, Leiden, The Netherlands, 1435-1457, 1988.

Blevins, R. D.: Formulas for natural frequencies and mode shape, Krieger Publishing, 506 pp., 2001.

Brenguier, F., Shapiro, N. M., Campillo, M., Ferrazzini, V., Duputel, Z., Coutant, O., and Nercessian, A.: Towards forecasting volcanic eruptions using seismic noise, Nat. Geosci., 1, 126-130, doi:10.1038/ngeo104, 2008.

Brückl, E. and Mertl, S.: Seismic monitoring of deep-seated mass movements, in: Proceedings of the INTERPRAEVENT International Symposium, Disaster Mitigation of Debris Flows, Slope 
Failures and Landslides, Marui, H., Niigata, Japan, 571-580, 2006.

Brunner, F. K., Hartinger, H., and Richter, B.: Continuous monitoring of landslides using GPS: a progress report, in: Geophysical Aspects of Mass Movements, edited by: Bauer, S. J. and Weber, F., Austrian Academy of Sciences, Vienna, 51-60, 2000.

Chambon, G., Schmittbuhl, J., and Corfdir, A.: Frictional response of a thick gouge sample : 2. Friction law and implications for faults, J. Geophys. Res., 111, B09309, doi:10.1029/2004JB003339, 2006.

Collins, B. D. and Sitar, N.: Processes of coastal bluff erosion in weakly lithified sands, Pacifica, California, USA, Geomorphology, 97, 483-501, doi:10.1016/j.geomorph.2007.09.004, 2008.

Cornelius, R. R. and Voight, B.: Seismological aspects of the 19891990 eruption at Redoubt Volcano, Alaska: the Materials Failure Forecast Method (FFM) with RSAM and SSAM seismic data, in: The 1989-1990 eruptions of Redoubt Volcano, Alaska, edited by: Miller, T. P. and Chouet, B. A., J. Volcanol. Geoth. Res., 62, 469-498, 1994.

Dewez, T. J. B., Rohmer, J., and Closset, L.: Laser survey and mechanical modelling of chalky sea cliff collapse in Normandy, France, in: Proceedings of the International Conference on Landslides and Climate Changes, Ventnor, England, 281-288, 2007.

Eberhardt, E., Spillmann, T., Maurer, H., Willenberg, H., Loew, S., and Stead, D.: The Randa Rockslide Laboratory: Establishing brittle and ductile instability mechanisms using numerical modelling and microseismicity, in: Proceedings of the 9th International Symposium on Landslides, edited by: Lacerda, W., Rio de Janeiro, Brasil, 481-487, 2004.

Endo, E. T. and Murray, T.: Real-time seismic amplitude measurement (RSAM): a volcano monitoring and prediction tool, B. Volcanol., 53, 533-545, 1991.

Ghabezloo, S. and Pouya, A.: Numerical modelling of the effect of weathering on the progressive failure of undeground limestone mines, in: EUROCK 2006 - Multiphysics Coupling and Long Term Behaviour in Rock Mechanics, edited by: Van Cotthem, A., Charlier, R., Thimus, J.-F., and Tshibangu, J.-P., Taylor and Francis Group, London, UK, 233-240, 2006.

Guéguen, Y. and Boutéca, M.: Mechanics of fluid saturated rocks, Elsevier Academic Press, 450 pp., 2004.

Hardy, H. R. and Kimble, E. J.: Application of high-frequency AE/MS techniques to rock slope monitoring, in: Proceedings of the 5th Conference on AE/MS Activity in Geologic Structures and Materials, edited by: Hardy, H. R., Trans Tech Publications, Clausthal-Zellerfeld, Germany, 457-477, 1991.

Homand, F. and Shao, J.-F.: Mechanical behaviour of a porous chalk and water-chalk interaction, Oil Gas Sci. Technol., 55, 591-609, 2000.

Jenkins, G. M. and Watts, D. G.: Spectral Analysis and its Applications, Holden-Day, Oakland, Calif., 525 pp., 1968.

Jones, D. I. G.: Handbook of viscoelastic vibration damping, John Wiley and Sons, 385 pp., 2001.

Kennedy, B. A. and Niermeyer, K. E.: Slope monitoring systems used in the prediction of a major slope failure at the Chuquicamata mine, Chile, in: Planning Open Pit Mines, edited by: van Rensburg, P. W. J., Proceedings of the Symposium on the Theoretical Background to the Planning of Open Pit mines With Special Referneces to Slope Stability, Balkema, Leiden, The Netherlands, 215-225, 1970.
Kolesnikov, Yu. I., Nemirovich-Danchenko, M. M., Goldin, S. V., and Seleznev, V. S.: Slope stability monitoring from microseismic field using polarization methodology, Nat. Hazards Earth Syst. Sci., 3, 515-521, 2003, http://www.nat-hazards-earth-syst-sci.net/3/515/2003/.

Lawn, B. R.: Fracture of brittle solids, 2nd edn., Cambridge University Press, 204 pp., 1993.

Mayer, H. and Siegel, A.: Monitoring slope motion and surface deformation by means of radar interferometry, in: Geophysical Aspects of Mass Movements, edited by: Bauer, S. J. and Weber, F., Austrian Academy of Sciences, 75-88, 2000.

Méric, O., Garambois, S., Malet, J.-P., Cadet, H., Gueguen, P., and Jongmans, D.: Seismic noise-base methods for soft-rock landslide characterization, B. Soc. Geol. Fr., 178, 137-148, 2007.

Mikoš, M., Vidmar, A., and Brilly, M.: Using a laser measurement system for monitoring morphological changes on the Strug rock fall, Slovenia, Nat. Hazards Earth Syst. Sci., 5, 143-153, 2005, http://www.nat-hazards-earth-syst-sci.net/5/143/2005/.

Ohnaka, M., A constitutive scaling law and a unified comprehension for frictional slip failure, shear fracture of intact rock, and earthquake rupture, J. Geophys. Res., 108, B22080, doi:10.1029/2000JB000123, 2003.

Parate, N. S.: The influence of water on the strength of limestones, Transactions of the Society of Mining, AIME, 254, 127-131, 1973.

Palmer, A. C. and Rice, J. R.: The growth of slip surfaces in the progressive failure of over-consolidated clay, P. R. Soc. Lond. A Mat., 332, 527-548, 1973.

Rhett, D. W. and Lord, C. J.: Water weakening in sedimentary rocks, in: Proceedings of the 38th US Symposium on Rock Mechanics, Washington DC, USA, 2001.

Rice, J. R.: The mechanics of earthquake rupture, in: Physics of the Earth's Interior, edited by: Dziewonski, A. M. and Boschi, E., Italian Physical Society and North-Holland Publ. Co., 555-649, 1980.

Risnes, R., Madland, M. V., Hole, M., and Kwabiah, N. K.: Water weakening of chalk - Mechanical effects of glycol and water, J. Petrol. Sci. Eng., 48, 21-36, 2005.

Roth, M., Dietrich, M., Blikra, L. H., and Lecomte, I.: Seismic monitoring of the unstable rock slope site at Aknes, Norway, in: 19th Annual Symposium on the Application of Geophysics to Engineering and Environmental Problems (SAGEEP), Seattle, Washington, 2005.

Rutter, E. H.: The influence of interstitial water on the rheological behaviour of calcite rocks, Tectonophysics, 14, 13-33, 1972.

Scholz, C. H.: The mechanics of earthquakes and faulting, Cambridge University Press, 471 pp., 2002.

Senfaute, G., Merrien-Soukatchoff, V., Morel, J., and Gourry, J.-C.: Microseismic monitoring applied to prediction of chalk cliff collapses and contribution of numerical modelling, in: Planning and Management on Fast Slope Movements - Prediction and Prevention for Risk Mitigation, Proceeding of the International Conference Instability, Naples, Italy, 463-468, 2003.

Senfaute, G., Duperret, A., and Lawrence, J. A.: Micro-seismic precursory cracks prior to rock-fall on coastal chalk cliffs: a case study at Mesnil-Val, Normandie, NW France, Nat. Hazards Earth Syst. Sci., 9, 1625-1641, 2009, http://www.nat-hazards-earth-syst-sci.net/9/1625/2009/. 
Shapiro, N. M., Campillo, M., Stehly, L., and Ritzwoller, M. H., High-resolution surface-wave tomography from ambient seismic noise, Science, 307, 1615-1618, 2005.

Snowdon, J. C.: Vibration and shocks in damped mechanical systems, John Wiley and Sons, 342 pp., 1968).

Spillmann, T., Maurer, H., Green, A. G., Heincke, B., Willenberg, H., and Husen, S.: Microseismic investigation of an unstable mountain slope in the Swiss Alps, J. Geophys. Res., 112, B07301, doi:10.1029/2006jb004723, 2007.

Vila, J., Macià, R., Kumar, D., Ortiz, R., Moreno, H., and Correig, A. M.: Analysis of the unrest of active volcanoes using variations of the base level seismic spectrum, J. Volcanol. Geoth. Res., 153, 11-20, 2006.

Voight, B.: A relation to describe rate-dependent material failure, Science, 243, 200-203, 1989.

Vutukuri, V. S.: The effect of liquids on the tensile strength of limestone, Int. J. Rock Mech. Min., 11, 27-29, 1974.
Willenberg, H., Spillmann, T., Eberhardt, E., Evans, K. F., Loew, S., and Maurer, H.: Multidisciplinary monitoring of progressive failure processes in brittle rock slopes - Concepts and system design, in: Landslides, edited by: Rybar, J., Stemberk, J., and Wagner, P., Proceedings of the 1st European Conference on Landslides, Prague, 477-483, 2002.

Willenberg, H., Loew, S., Eberhardt, E., Evans, K. F., Spillmann, T., Heincke, B., Maurer, H., and Green, A. G.: Internal structure and deformation of an unstable crystalline rock mass above Randa (Switzerland), Eng. Geol., 101(1-2), 15-32, doi:10.1016/j.enggeo.2008.01.015, 2008.

Zvelebil, J. and Moser, M.: Monitored based time-prediction of rock falls: Three case histories, Phys. Chem. Earth, Pt. B, 26, 159-167, 2001. 